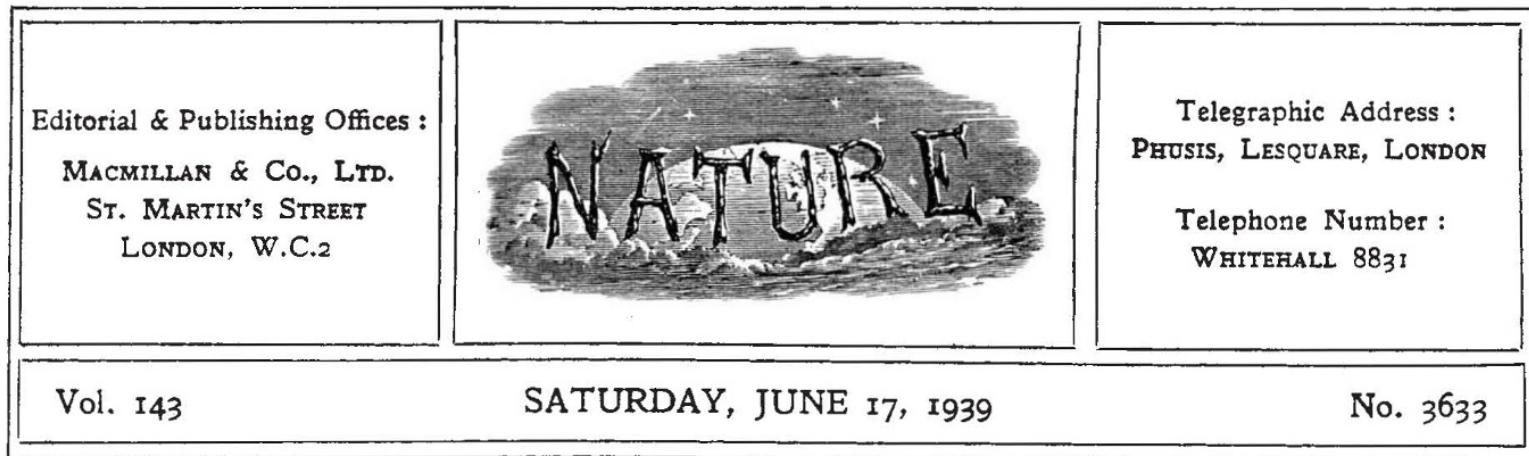

\title{
Discipline in Freedom
}

$\mathrm{T}$ HE three lectures which Lord Baldwin delivered at Toronto in April last, inaugurating the lectureship founded in memory of Sir Robert Falconer, have distinct claims on the attention of scientific workers. His analysis of the ideals and dangers of democracy and of the opposing forces at the present time both clarifies the fundamental issues and sounds a call to service to which men of science will not wish to be indifferent.

The supreme task, Lord Baldwin asserted, is that of combining freedom and discipline; in these lectures he adds one more voice to the many that have summoned scientific workers and their fellows to the defence of freedom of thought and speech and to the necessity of self-discipline and spontaneous service in order to enable the survival of our ideals. Lord Baldwin also insists on the necessity for having regard to the trends of our modern industrial system, for a wide perspective and not partial or biased views, and for imaginative handling of the possibilities which physiological knowledge and medical science offer us of elim. inating some of the fundamental causes of industrial unrest by minimizing the strain or stress due to speed or monotony.

Here indeed is scope for further investigation, and not even the immediate exigencies of national defence should be allowed to stand in the way of increased effort in such fields as those in which the National Institute of Industrial Psychology and the Industrial Health Research Board are working. The work of the latter Board, it should be remembered, owes its origin to endeavours to safeguard the health of munition workers and increase their efficiency. A national defence policy must have full regard to the health of those who answer the call to national service, whether in working or in leisure hours. The careless destruction of amenities may have serious consequences to the national efficiency or morale in more ways than one. The protests against the proposal to erect a steel works in the Edale district find strong justification in the threat the proposal may well involve to the health of the industrial populations which have benefited so much from the availability of that district for recreation.

This is indeed a particular aspect of the problem of maintaining standards, which Lord Baldwin reminds us is an ever-present danger in a democracy. The coalition of paganism and machinery which makes the situation grave to-day challenges almost every one of the essential values cherished in a democracy-human personality, freedom and truth. Universities have their special responsibilities in maintaining those standards, and above all in supplying leaders who will be loyal to them and adamant in their service. The pursuit of intellectual truth is the chief object of university training, as the advancement of knowledge is one of the chief functions of a university.

The logical sequel to the pursuit of intellectual truth in the university is that the community is entitled to expect those leaving a university to have trained minds able to give dispassionate consideration to varied problems. This point was made by Sir Robert Pickard, vice-chancellor of the University of London, in addressing the new graduates at the annual degree-giving ceremony last month. He warned them that their academic distinctions were based mainly upon book learning, and gave them no claim to special consideration, except in so far as their training had taught them to develop unprejudiced minds able to weigh evidence. Such 
critical interest in world affairs is indeed the plain duty of all thoughtful men.

Sir Robert Pickard also referred to the attacks which have been made in recent years upon mental freedom. A constant desire for truth, a hunger for knowledge, a balanced judgment and earnest consideration for the views of others who might not share their views on different problems, these are the hall-marks of a truly educated man. This attitude can only be achieved in an atmosphere of academic freedom, wherein the mind can follow the pursuit of knowledge untrammelled by the dictates of State or other institutions. Without mental freedom, Sir Robert rightly said, humanity and civilization must surely perish. It is a precious gift, which all who cherish learning would wish to hand on undiminished in value to succeeding generations.

Nevertheless, the path to knowledge, as Sir David Munro pointed out in his rectorial address at St. Andrews, is a disciplined path. The freedom we still possess in Great Britain to think for ourselves, to study the particular fields of knowledge that interest us, to act fearlessly on the dictates of our opinions and ideals involves discipline of the mind as well as of the body. Lack of self-discipline, Sir David Munro asserted, is what most endangers freedom.

The discipline and freedom of our schools and universities are not always enough to develop innate qualities of leadership. Sir David Munro pointed out that sometimes neither school nor college life fosters the eagerness and zest for life without which freedom is an empty gift and there is little worth disciplining. Such failure does not always lie in missed opportunities or in the biological make-up of the individual. What is lacking is interest or desire, in default of which faculties lie dormant and the tide of life runs low. Zest, he contended, is what matters ; but without discipline it is unbridled, and without freedom it is stifled.

Nor is this reminder one for youth alone. It may be that youth has its special advantages and opportunities to be experimental. One of democracy's greatest needs to-day is for creative minds, willing and able to experiment wisely and constructively. A root cause of our failure to develop the new technique of social control which Lord Baldwin desiderated is this lack of zest and lack of interest in the social consequences of scientific discovery on the part of scientific workers themselves. That indifference is passing, but until disciplined enthusiasm in such matters is char- acteristic of the overwhelming majority of scientific workers, we can scarcely hope to progress at the rate desired.

What we have yet to take account of is the changed condition of the struggle. New social techniques are available for directing mass behaviour in obedience to one man's will; new economic techniques for the industrial regimentation of the workers; new financial techniques for the ruthless taxation of rich and poor, for the plunder of aliens and the enemy within the gates. Plans can be prepared in secret and applied overnight for the enslavement of a whole nation and for the swift incarceration of its leaders by the hundred or by the thousand as required.

Conditions such as these impose on all democracies the necessity of attaining new levels of technical efficiency for self-defence and in co-operation. Moreover, there must be a devotion to the ideals of social justice and individual freedom inspired by a passion and zest for life which more than match the idolatrous worship of the State and brute force in the totalitarian countries. Grave as may be the threat which the menace of war offers to the world at the moment, if those in whose hands the defence of truth and freedom still remains are inspired, not by academic loyalty, but by a passionate zest for life, the danger may yet be averted, and advances in the standards of life for multitudes which social and scientific progress have made possible may be realized.

This is above all a question of leadership. It is not to be achieved by the pursuit of academic freedom as a thing apart from life, but by unflinching devotion to whatever that service and quest may involve in the social and political world, no less than within the walls of a university or laboratory. It demands that scientific workers themselves be willing to seek out and deal with all that restricts the full freedom of investigation or exposition and interpretation, or retards the application of the results of their work in the service of mankind. It means in practice the close study or investigation of many problems or even whole fields as yet largely unexplored. It means the acceptance of responsibilities for leadership and service and the development of such capacities, no less than of technical or scientific qualifications. But it involves above all an enthusiasm, a zest for life, a vision and sense of values and loyalty to ideals implicit alike in real leadership and in that moral disarmament for which the call was issued with the appeal for national service. 